\title{
Luminescent characteristics of InGaAsP/InP multiple quantum well structures by impurity-free vacancy disordering
}

\author{
J. Zhao ${ }^{\text {a }}$, Z.C. Feng ${ }^{\text {b,* }}$, Y.C. Wang ${ }^{\text {a }}$, J.C. Deng ${ }^{\text {a }}$, G. Xu ${ }^{\mathrm{c}}$ \\ ${ }^{a}$ College of Physics and Electronic Information, Tianjin Normal University, Tianjin 300074, PR China \\ ${ }^{\mathrm{b}}$ Graduate Institute of Electro-Optical Engineering and Department of Electrical Engineering, National Taiwan University, Taipei, Taiwan 106-17, ROC \\ ${ }^{\mathrm{c}}$ Department of Materials Science and Engineering, McMaster University, Hamilton, Canada L8S 4 L7
}

Available online 11 August 2005

\begin{abstract}
InGaAsP/InP multiple quantum wells with quantum well intermixing (QWI) have been prepared by Impurity-Free Vacancy Disordering (IFVD). The luminescent characteristics were investigated using photoluminescence (PL) and photoreflectance (PR), from which the band gap blueshift was observed. $\mathrm{Si}_{3} \mathrm{~N}_{4}, \mathrm{SiO}_{2}$ and $\mathrm{SOG}$ (spin on glass) were used for the dielectric layer to enhance intermixing from the outdiffusion of Group III atoms. All samples were annealed by rapid thermal annealing (RTA). The results indicate that the band gap blueshift varies with the dielectric layers and the annealing temperature. The $\mathrm{SiO}_{2}$ capping was successfully used with an InGaAs cladding layer to cause larger band tuning effect in the InGaAs/InP MQWs than the $\mathrm{Si}_{3} \mathrm{~N}_{4}$ capping with an InGaAs cladding layer. On the other hand, samples with the $\mathrm{Si}_{3} \mathrm{~N}_{4}-\mathrm{InP}$ cap layer combination also show larger energy shifts than that with $\mathrm{SiO}_{2}-\mathrm{InP}$ cap layer combination.
\end{abstract}

(C) 2005 Elsevier B.V. All rights reserved.

PACS: 78.40.Fy; 78.55.Cr; 81.05.Ea; 81.15.Hi

Keywords: InP; InGaAsP; Molecular beam epitaxy; Quantum well; Impurity-free vacancy disordering (IFVD); Optical properties

\section{Introduction}

Quantum well intermixing (QWI) technology has attracted much interest in recent years for the fabrication of various optoelectronic devices, such as high power semiconductor lasers and photonic integrated devices and circuits $[1-6]$. In order to realize the monolithic integration of active and passive optoelectronic devices and components, different techniques are currently under investigation, such as selective area growth and growth-etch-regrowth. Regrowth requires many steps of etching and it is often associated with low efficiency and poor yield [2]. Also, the contamination and defects at etched and regrowth interface are difficult to avoid. As an alternative approach, post growth QWI becomes a more attractive technique, which can change the QW shape and composition by intermixing wells and barriers in QWs giving rise to a blueshifted band

\footnotetext{
* Corresponding author. Tel.: +8862 33663543; fax: +886 223677467
}

E-mail address: zcfeng@cc.ee.ntu.edu.tw (Z.C. Feng). gap. This postgrowth controlling of QW profiles, or the post-tuning of optical band gap energy can be realized by impurity-induced intermixing or impurity-free vacancyenhanced intermixing [7]. Several technical approaches have been explored to achieve this purpose, including Impurity Induced Disordering (IID) [8,9], Implant Induced Composition Disordering (IICD) [2,10-12], and ImpurityFree Vacancy Disordering (IFVD) [2,13-15]. Among them, IFVD technique is more promising because it can maintain the high crystal quality and low optical propagation loses without introducing free-carrier concentration.

IFVD usually involves a deposition of a dielectric capping layer such as $\mathrm{SiO}_{2}$ and $\mathrm{Si}_{3} \mathrm{~N}_{4}$ on the top of QWs and post rapid thermal annealing (RTA) at elevated temperature. Vacancies can be created at the dielectric-semiconductor interface due to the out-diffusion, for example $\mathrm{Ga}$ atoms, from the semiconductor layers into the dielectric region. The diffusion of these vacancies into the structure can enhance the QW intermixing, leading to a large blueshift of the QW band gap energy with minimum effect 
on their electrical and optical properties [16,17]. By using the IFVD technique, QW intermixing has been realized on multiple quantum well (MQW) structures of $\operatorname{In}_{0.53} \mathrm{Ga}_{0.47} \mathrm{As} /$ InP [13], $\mathrm{Al}_{0.3} \mathrm{Ga}_{0.7} \mathrm{As} / \mathrm{GaAs}$ and $\mathrm{In}_{0.2} \mathrm{Ga}_{0.8} \mathrm{As} / \mathrm{GaAs}$ [14], $\mathrm{In}_{1-x} \mathrm{Ga}_{x} \mathrm{As} / \mathrm{InP}$ [2,3], $\mathrm{In}_{1-x} \mathrm{Ga}_{x} \mathrm{As} / \mathrm{In}_{1-x} \mathrm{Ga}_{x} \mathrm{As}_{1-y} \mathrm{P}_{y}$ [2], $\mathrm{In}_{0.76} \mathrm{Ga}_{0.24} \mathrm{As}_{0.85} \mathrm{P}_{0.15} / \mathrm{In}_{0.76} \mathrm{Ga}_{0.24} \mathrm{As}_{0.52} \mathrm{P}_{0.48}$ [4], and $\mathrm{In}_{0.2} \mathrm{Ga}_{0.8} \mathrm{As} / \mathrm{GaAs}$ [15].

It is found that by selecting a proper combination, the properties of capping layers have important influence on the degree of QWI and band gap blueshifts. The $\mathrm{SiO}_{2}$ dielectric cap is porous to out-diffusion of $\mathrm{Ga}$ atoms, thus generating group III vacancies which results in diffusion of group III atoms from the barrier to the well [18]. As a result, effective band gap of the QW is widened. If the cap does not react with significant $\mathrm{Ga}$ atoms, QWI is suppressed. For the $\mathrm{GaAs}-\mathrm{AlGaAs} \mathrm{QW}$ system, $\mathrm{SiO}_{2}$ cap has been generally used to promote QWI while $\mathrm{SiN}_{x}$ is used as a mask to prevent or suppress QWI because the $\mathrm{SiO}_{2}$ cap layer induces a relatively larger blueshift than $\mathrm{SiN}_{x}$ cap layer [5,6,19]. A very thin $\mathrm{SiO}_{2}$ cap is also expected to suppress QWI because of saturation of the diffused Ga atoms [20].

For the InGaAs/InP system, the $\mathrm{SiO}_{2}$ cap is also employed to enhance QWI while $\mathrm{Si}_{3} \mathrm{~N}_{4}, \mathrm{Ga}_{2} \mathrm{O}_{3}$ and $\mathrm{SrF}_{2}$ are used to suppress the intermixing [15]. By changing the deposition pressure of $\mathrm{SiO}_{x}$ capping layers, variable blueshifts can be obtained [15]. It is also reported for this system that the $\mathrm{SiO}_{2}-\mathrm{In}_{0.53} \mathrm{Ga}_{0.47}$ As combination produces a band gap blueshift while $\mathrm{SiO}_{2}-\mathrm{InP}$ or $\mathrm{SiN}_{x}-\mathrm{InGaAs}$ cap layer combinations do not show significant energy shift [13].

The effect of semiconductor-capping layer combination on QWI for the $\mathrm{In}_{1-x} \mathrm{Ga}_{x} \mathrm{As} / \mathrm{In}_{1-x} \mathrm{Ga}_{x} \mathrm{As}_{1-y} \mathrm{P}_{y}$ MQW structures showed similar trends [2]. The samples with the $\mathrm{InGaAs} / \mathrm{SiO}_{2}$ capping layer combination exhibited a higher degree of intermixing than those with the $\mathrm{InP} / \mathrm{SiO}_{2}$ capping layer combination after RTA treatment. This is attributed to the fact that InP has no $\mathrm{Ga}$ atom and possesses a lower thermal expansion coefficient than InGaAs [2].

However, more penetrating and systematic studies on the QWI in various quantum well systems and the factors influencing the band gap blueshifts as well as their mechanisms are still needed to be explored. In this paper, a systematic investigation of the luminescent characteristics of InGaAsP/InP MQW system using $\mathrm{SiO}_{2}, \mathrm{Si}_{3} \mathrm{~N}_{4}$ and SOG (spin on glass) as dielectric layers with different cladding layer in IFVD is reported. Photoluminescence (PL) was measured by a Fourier Transform Infrared (FTIR) PL system. Photoreflectance (PR) measurements on these samples were used to investigate further the behavior of band gap blueshift. To our knowledge, only a few work [5] was reported in the literature with measuring band gap blueshift by PR for this material system. We also attempt to analyze the band gap luminescent characteristics and the effects from different combinations of cladding layer and dielectric layer, such as $\mathrm{InP}-\mathrm{SiO}_{2}$ and $\mathrm{InP}-\mathrm{Si}_{3} \mathrm{~N}_{4}$.

\section{Experiment}

Two typical samples were chosen in this paper. Both samples $\mathrm{A}$ and $\mathrm{B}$ are with $\mathrm{InGaAsP} / \mathrm{InP} \mathrm{MQW}$ layer structures, consisting of three quantum wells, designed to emit at wavelength of $1.57 \mu \mathrm{m}$ and $1.55 \mu \mathrm{m}$, respectively. They were grown by Gas Source Molecular Beam Epitaxy (GSMBE). The details of the samples are shown in Table 1. Sample A was cut and divided into three groups with capped dielectric layers of $\mathrm{SiO}_{2}$ and $\mathrm{Si}_{3} \mathrm{~N}_{4}$ by way of plasma enhance chemical vapor deposition (PECVD) and SOG (spin on glass) by spin coating at $3000 \mathrm{rpm}$ for $45 \mathrm{~s}$. The thickness of all the dielectric layers is about $200 \mathrm{~nm}$.

Table 1

Schematic layer structure of the InGaAsP/InP MQW samples studied

\begin{tabular}{|c|c|c|c|c|c|c|c|}
\hline \multicolumn{4}{|l|}{ Sample A } & \multicolumn{4}{|l|}{ Sample B } \\
\hline Material & $\begin{array}{l}\text { Band gap } \lambda_{\mathrm{g}} \\
(\mu \mathrm{m})\end{array}$ & $\begin{array}{l}\text { Carrier } \\
\text { concentration } \\
\left(\mathrm{cm}^{-3}\right)\end{array}$ & $\begin{array}{l}\text { Thickness } \\
d(\mathrm{~nm})\end{array}$ & Material & $\begin{array}{l}\text { Band } \\
\text { gap }(\mu \mathrm{m})\end{array}$ & $\begin{array}{l}\text { Carrier } \\
\text { concentration } \\
\left(\mathrm{cm}^{-3}\right)\end{array}$ & $\begin{array}{l}\text { Thickness } \\
(\mathrm{nm})\end{array}$ \\
\hline InP (Heimplanted) & & $p=1 \mathrm{e} 18$ & 100 & InP & & (undoped) & 100 \\
\hline InP & & $p=6 \mathrm{e} 17$ & 25 & InGaAs (undoped) & & & 5 \\
\hline InGaAsP & 1.15 & $p=5 \mathrm{e} 17$ & 80 & InP & & $p=1 \mathrm{e} 18$ & 200 \\
\hline InGaAsP & 1.24 & $p=5 \mathrm{e} 17$ & 70 & InP & & $p=5 \mathrm{e} 17$ & 200 \\
\hline InGaAsP & 1.58 & $p=5 \mathrm{e} 17$ & 5 & InP (Heimplanted) & & $p=5 \mathrm{e} 17$ & 40 \\
\hline InGaAsP & 1.24 & $p=5 \mathrm{e} 17$ & 10 & InP & & $p=5 \mathrm{e} 17$ & 5 \\
\hline InGaAsP & 1.58 & $p=5 \mathrm{e} 17$ & 5 & InGaAsP & 1.15 & $p=5 \mathrm{e} 17$ & 100 \\
\hline InGaAsP & 1.24 & $p=5 \mathrm{e} 17$ & 10 & InGaAsP & 1.24 & (undoped) & 60 \\
\hline InGaAsP & 1.58 & $p=5 \mathrm{e} 17$ & 5 & $\begin{array}{l}\text { QWs: } \mathrm{In}_{0.758} \mathrm{Ga}_{0.242} \mathrm{As}_{0.83} \mathrm{P}_{0.17} \\
\text { Barriers: } \operatorname{In}_{0.758} \mathrm{Ga}_{0.242} \mathrm{As}_{0.525} \mathrm{P}_{0.475}\end{array}$ & & & $\begin{array}{l}3 * 5 \\
2 * 10\end{array}$ \\
\hline InGaAsP & 1.24 & $p=5 \mathrm{e} 17$ & 70 & InGaAsP & 1.24 & (undoped) & 30 \\
\hline InGaAsP & 1.15 & $n=5 \mathrm{e} 17$ & 80 & InGaAsP & 1.15 & $n=5 \mathrm{e} 17$ & 30 \\
\hline $\begin{array}{l}\text { InP } \\
\mathrm{n}^{+}-\text {InP substrate }\end{array}$ & & $n=1 \mathrm{e} 18$ & 500 & $\begin{array}{l}\text { InP } \\
n^{+}-\text {InP substrate }\end{array}$ & & $n=1 \mathrm{e} 18$ & 500 \\
\hline
\end{tabular}

Values of carrier concentration and thickness are provided from the vender of MBE growth. 
Samples with the SOG (a mixture of organic and inorganic compounds commercially purchased) cap were then baked at $200{ }^{\circ} \mathrm{C}$ for $2 \mathrm{~h}$ under pure nitrogen ambit protection. Sample B was divided into two groups remarked B1 and B2. B1 was same as B listed in Table 1, while B2 was with the InP cladding layer etched away using a corrosive acid solution $\left(\mathrm{HCl} / \mathrm{H}_{3} \mathrm{PO}_{4}=1: 1\right)$. Subsequently, samples B1 and $\mathrm{B} 2$ were deposited with $\mathrm{SiO}_{2}$ and $\mathrm{Si}_{3} \mathrm{~N}_{4}$, respectively, with a thickness of about $200 \mathrm{~nm}$, both by PECVD.

After the GSMBE growth, samples were then annealed in a rapid thermal annealing (RTA) furnace in the temperature range of $650{ }^{\circ} \mathrm{C}-850{ }^{\circ} \mathrm{C}$ in $50{ }^{\circ} \mathrm{C}$ steps. The annealing time for all samples was kept for $30 \mathrm{~s}$. During RTA the samples were covered with a piece of semi-insulating-GaAs face to face to minimize the decomposition of InP and possible contamination. All annealing processing are under pure nitrogen.

Photoluminescence measurements were performed at the temperature $300 \mathrm{~K}$. The excitation source was an Argon ion laser with the wavelength of $514.5 \mathrm{~nm}$. The Photoreflectance (PR) spectra were measured by a modulation system. The modulation source was an $\mathrm{He}-\mathrm{Ne}$ laser with the wavelength of $632.8 \mathrm{~nm}$.

\section{Results and discussion}

Room temperature PL spectra are shown in Fig. 1 for the as-grown sample A and disordered InGaAsP multi-quantum well structures after RTA at $800{ }^{\circ} \mathrm{C}$ for $30 \mathrm{~s}$ with $\mathrm{SiO}_{2}$ and $\mathrm{Si}_{3} \mathrm{~N}_{4}$ encapsulating layer, respectively. The peak position of the PL spectrum for the as grown sample $\mathrm{A}$ is at $1.571 \mu \mathrm{m}$ $(0.789 \mathrm{eV})$, corresponding to the electron transition from the first level of electronic subband to the first level of heavy hole (E1-HH1) and light hole subband (E1-LH1). From Fig. 1 , we can find that the band gap blueshift depends on the dielectric layer. Sample A with an $\mathrm{Si}_{3} \mathrm{~N}_{4}$ capped layer obtained larger blueshift. In order to find the dependence of

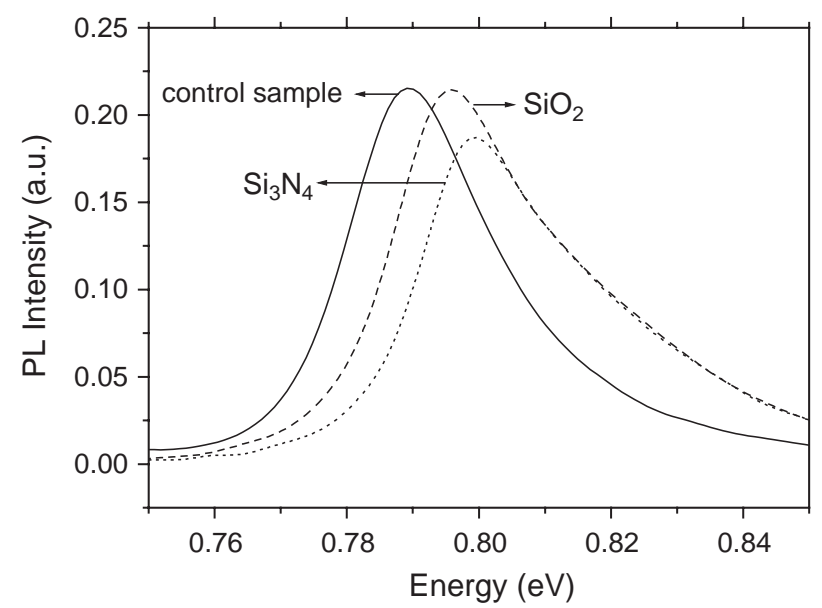

Fig. 1. The PL spectra of the as-grown control sample and $\mathrm{SiO}_{2}, \mathrm{Si}_{3} \mathrm{~N}_{4}$ covered samples (Group A).

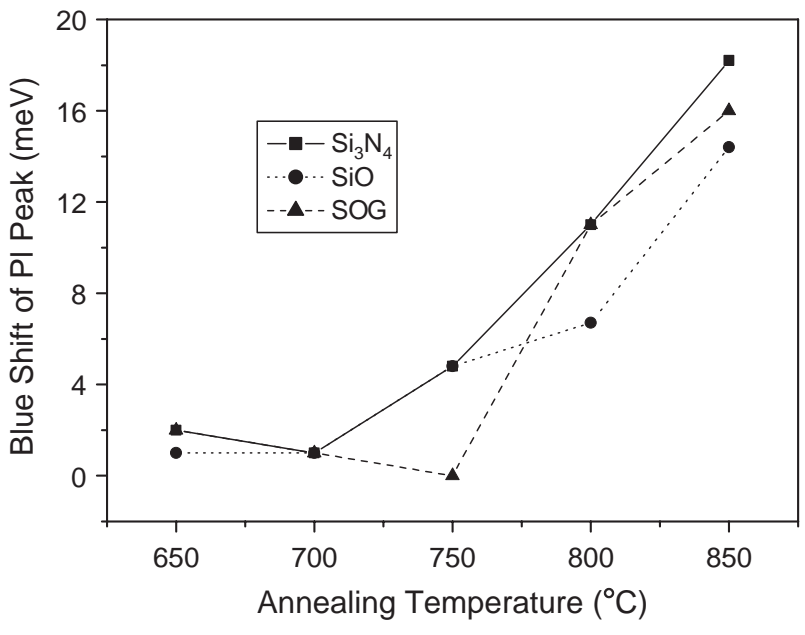

Fig. 2. The temperature dependence of blueshift for different dielectric covered samples (Group A).

the band gap blueshift on the annealing temperature, the samples covered with $\mathrm{Si}_{3} \mathrm{~N}_{4}, \mathrm{SiO}_{2}$ and $\mathrm{SOG}$ were annealed at the temperature of $650,700,750,800$ and $850{ }^{\circ} \mathrm{C}$, respectively, under pure nitrogen protection at atmospheric pressure.

Fig. 2 shows the annealing temperature dependence of band gap shift. It can be observed that the band gap of PL peak varies with the RTA temperature. For low annealing temperature range of $650-750{ }^{\circ} \mathrm{C}$, the PL peak has little change, however, when the annealing temperature was beyond $750{ }^{\circ} \mathrm{C}$, the PL peak moves to short wavelength evidently. This may be due to the impurity-free vacancy enhanced interdiffusion created by the dielectric layer deposition and annealing.

On the other hand, we also performed photoreflectance (PR) measurements in accordance with the results of PL spectra, as shown in Fig. 3. It shows that PR results are consistent with the PL results. This indicates that PR can be used as a supplementary way to study the luminescent

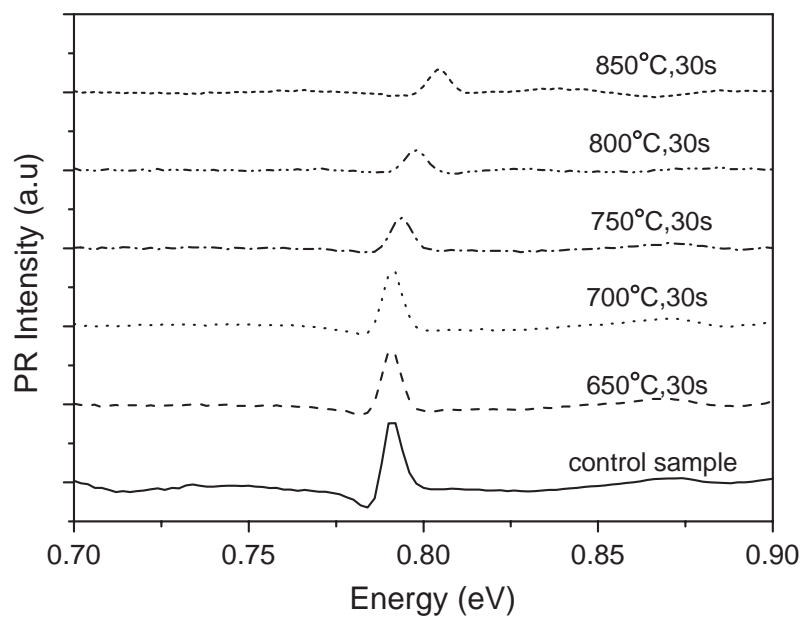

Fig. 3. Band gap blueshift measured by PR with different annealing temperatures (for samples in Group A). 
characteristics of the band gap shift. Furthermore, PR spectra can provide some other information, for example, some detailed data about different layer luminescent characteristics through analyzing PR spectra [5].

In order to analyze the effects of the combination of the cladding layer and dielectric covered layer, the annealing temperature dependence of the band gap blueshift for samples B1 and B2 with different dielectric layers were further studied, based upon the PL data. Sample B1 has an InP cladding structure, and sample B2 has an InGaAs cladding layer. Both samples B1 and B2 have the same MQWs except for the cladding layer. These two types of samples were measured under the same experimental condition in order to examine their band gap blueshift.

Fig. 4 shows the dependences of the blueshift PL peak on the annealing temperature, caused by different covered layer of $\mathrm{Si}_{3} \mathrm{~N}_{4}$ and $\mathrm{SiO}_{2}$, respectively. It can be observed that the induced blueshift from the sample with the $\mathrm{InP}-\mathrm{Si}_{3} \mathrm{~N}_{4}$ combination is larger than that with the $\mathrm{InP}-\mathrm{SiO}_{2}$ combination. For example, the blueshift of the sample with the
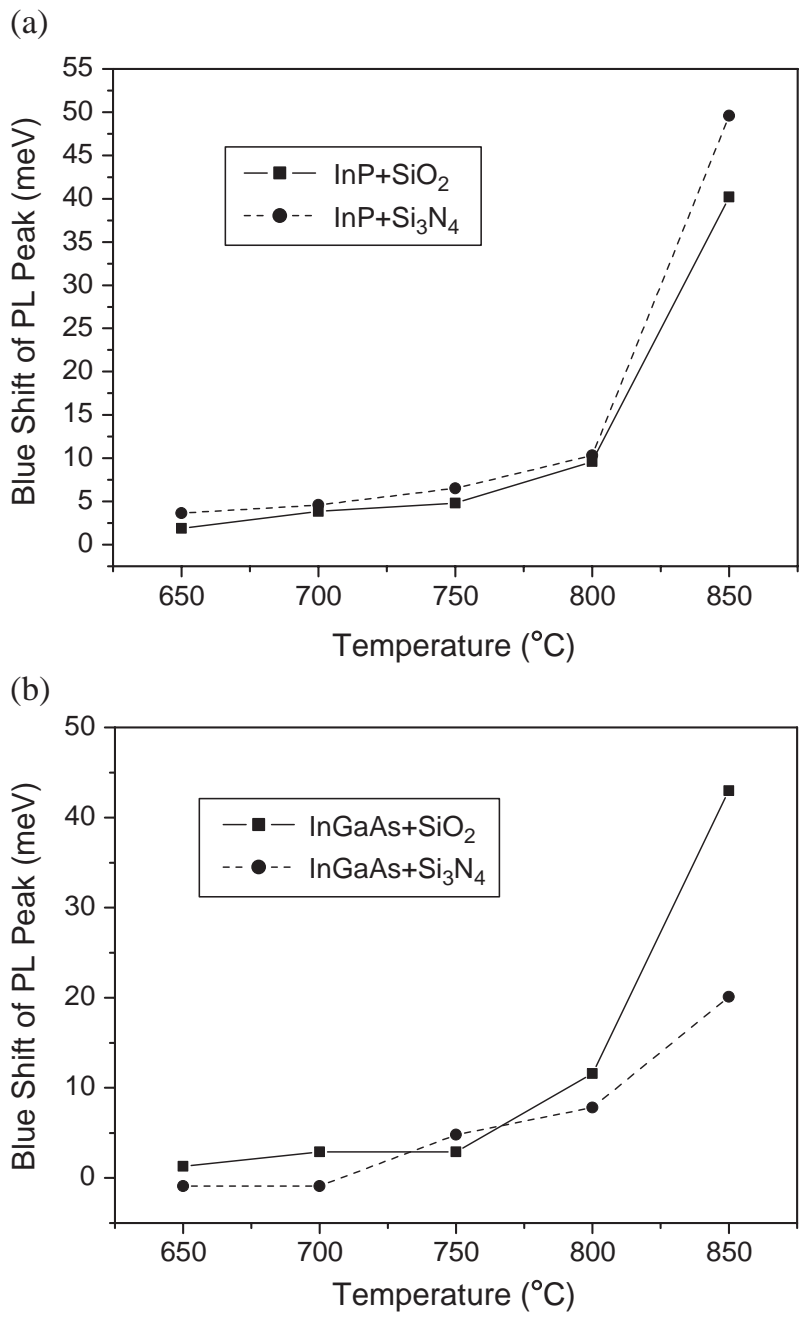

Fig. 4. The temperature dependences of blueshift for the samples with (a) $\mathrm{InP}-\mathrm{SiO}_{2}$ and $\mathrm{InP}-\mathrm{Si}_{3} \mathrm{~N}_{4}$ combination layers, and (b) $\mathrm{InGaAs}-\mathrm{SiO}_{2}$ and InGaAs $-\mathrm{Si}_{3} \mathrm{~N}_{4}$ combination layers (for samples in Group B).
$\mathrm{InP}-\mathrm{Si}_{3} \mathrm{~N}_{4}$ cap layer combination reaches $50 \mathrm{meV}$ at 850 ${ }^{\circ} \mathrm{C}$, but the blueshift of the sample with the $\mathrm{InP}-\mathrm{SiO}_{2}$ cap layer combination is only $40 \mathrm{meV}$ at the same annealing temperature. On the other hand, the combination of InGaAs $-\mathrm{Si}_{3} \mathrm{~N}_{4}$ covered layer caused a blueshift of 20 $\mathrm{meV}$, however the combination of $\mathrm{InGaAs}-\mathrm{SiO}_{2}$ reached a value of $43 \mathrm{meV}$.

From these results, we can conclude that the combination layer of $\mathrm{InP}-\mathrm{Si}_{3} \mathrm{~N}_{4}$ or $\mathrm{InGaAs}-\mathrm{SiO}_{2}$ can create larger band gap blueshift in comparison to the combination of $\mathrm{InP}-\mathrm{SiO}_{2}$ and $\mathrm{InGaAs}-\mathrm{Si}_{3} \mathrm{~N}_{4}$. The reason for these experimental results is not very clear yet, but in our opinion, it can be explained as follows: the vacancies are produced in both groups III and V. It is known that in GaAs material the following reactions are prompted to produce large number of vacancies at the interface:

$4 \mathrm{GaAs}+3 \mathrm{SiO}_{2} \Leftrightarrow 4 \mathrm{Ga}+2 \mathrm{As}_{2} \mathrm{O}_{3}+3 \mathrm{Si}$

$\mathrm{As}_{2} \mathrm{O}_{3}+2 \mathrm{GaAs} \Leftrightarrow \mathrm{Ga}_{2} \mathrm{O}_{3}+4 \mathrm{As}$.

Our results indicate that the vacancies generated by the $\mathrm{InP}-\mathrm{SiO}_{2}$ combination are less than that by the InGaAs$\mathrm{SiO}_{2}$ combination layers because of the absence of $\mathrm{Ga}$. As for the group $\mathrm{V}$ vacancies, we cannot provide the detailed reactions as to how the vacancies are produced. This may be due to the effects on the combination of the cladding layer and dielectric layers. Further penetrating investigation is needed.

\section{Conclusion}

In conclusion, we have studied the dependence of the band gap blueshift on the annealing temperature and dielectric layers from the InGaAsP/InP multiple quantum wells prepared by Impurity-Free Vacancy Disordering (IFVD). Both PL and PR results, which are consistent each other, showed that this band gap blueshift increases with the annealing temperature for all samples especially when the temperature is over $750{ }^{\circ} \mathrm{C}$. Our results indicate that $\mathrm{PR}$ can also be used as a supplementary technique, in addition to PL, to study the band gap blueshift. On the other hand, to obtain larger energy shift the optimal selected cap layer combination with the dielectric layer is necessary. From our experiments the combination of $\mathrm{InP}-\mathrm{Si}_{3} \mathrm{~N}_{4}$ or InGaAs$\mathrm{SiO}_{2}$ is better than the combination of $\mathrm{InGaAs}-\mathrm{Si}_{3} \mathrm{~N}_{4}$ or $\mathrm{InP}-\mathrm{SiO}_{2}$.

\section{Acknowledgments}

The authors would like to thank Dr. B. Robinson at McMaster University Canada for providing the GSMBE samples, Dr. P. Jin at Institute of Semiconductors, Beijing, for PR measurements, Prof. S. J. Chua at Institute of Materials Research and Engineering, Singapore for help and 
support of PL measurements, and X.D. Zhang and H.H. Liu for technical assistants. This project at Tianjin Normal University is supported by the Nature Science Foundation of China (NSFC) with a contract number of 60276013 . The work at National Taiwan University was supported by funds from National Science Council of Republic of China, NSC 93-2218-E-002-011 and 93-2215-E-002-035.

\section{References}

[1] D. Hofstetter, B. Maisenhölder, H.P. Zappe, IEEE J. Sel. Top. Quantum Electron. 4 (1998) 794.

[2] H.-S. Kim, J.W. Park, D.K. Oh, K.R. Oh, S.J. Kim, I.-H. Choi, Semicond. Sci. Technol. 15 (2000) 1005.

[3] J. Zhao, Y. Wang, Surf. Coat. Technol. 131 (2000) 340

[4] J.H. Teng, J.R. Dong, S.J. Chua, M.Y. Lai, B.C. Foo, D.A. Thompson, B.J. Robinson, A.S.W. Lee, John Hazell, Irwin Sproule, J. Appl. Phys. 92 (2002) 4330.

[5] R. Kudrawiec, G. Sek, W. Rudno-Rudzinski, J. Misiewicz, J. Wojcik, B.J. Robinson, D.A. Thompson, P. Mascher, Mater. Sci. Eng., B, Solid-State Mater. Adv. Technol. 101 (2003) 137.

[6] B.E. Gordon, A.S.W. Lee, D.A. Thompson, B.J. Robinson, Semicond. Sci. Technol. 18 (2003) 782.

[7] J.H. Marsh, Semicond. Sci. Technol. 8 (1993) 1136.
[8] D. Gdeepe, N. Holonyak Jr., J. Appl. Phys. 64 (1988) R93.

[9] P.G. Piva, R.D. Goldberg, I.V. Mitchell, H. Chen, R.M. Feenstra, G.C. Weatherly, D.W. McComb, G.C. Aers, P.J. Poole, S. Charbonneau, Appl. Phys. Lett. 72 (1998) 1599.

[10] S.R. Andrew, J.H. Marsh, M.C. Holland, A.H. Kean, IEEE Photonics Technol. Lett. 4 (1992) 426.

[11] B.B. Elenkrig, D.A. Thompson, J.G. Simmons, D.M. Bruce, Yu Si, Jie Zhao, J.D. Evans, I.M. Templeton, Appl. Phys. Lett. 65 (1994) 1239.

[12] M. Paquette, J. Beauvais, J. Beerens, P.J. Poole, S. Charbonneau, C.J. Miner, C. Blaauw, Appl. Phys. Lett. 71 (1997) 3749.

[13] J.H. Lee, S.K. Si, Y.B. Moon, E.J. Yoon, S.J. Kim, Electron. Lett. 33 (1997) 1179.

[14] G. Li, S.J. Chua, S.J. Xu, X.C. Wang, A. Saher Helmy, Mao-Long Ke, J.H. Marsh, Appl. Phys. Lett. 73 (1998) 3393.

[15] J.S. Yu, J.D. Song, Y.T. Lee, J. Appl. Phys. 92 (2002) 1386.

[16] S. Burkner, M. Maier, E.C. Larkins, W. Rothemund, E.P. O'Reilly, J.D. Ralston, J. Electron. Mater. 24 (1995) 805.

[17] G. Li, S.J. Chua, J.H. Teng, W. Wang, Z.C. Feng, H. Huang, T. Osipowicz, J. Vac. Sci. Technol., B 17 (1999) 1507.

[18] F. Camacho, E.A. Avrutin, P. Cusumano, A.S. Helmy, A.C. Bryce, J.H. Marsh, IEEE Photonics Technol. Lett. 9 (1997) 1208.

[19] W.J. Choi, S.M. Han, S.I. Shah, S.G. Choi, D.H. Woo, S. Lee, S.H. Kim, J.I. Lee, K.N. Kang, J. Cho, IEEE J. Sel. Top. Quantum Electron. 4 (1998) 624.

[20] N. Shimada, Y. Fukumoto, M. Uemukai, T. Suhara, H. Nishihara, A. Larsson, Jpn. J. Appl. Phys. Part 139 (2000) 5914. 